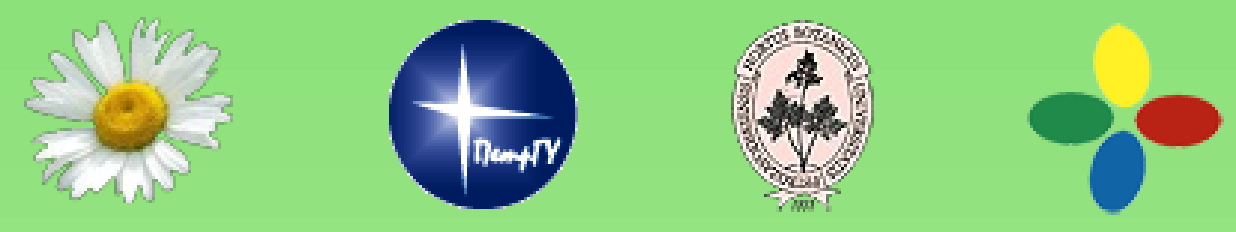

\title{
HORTUS BOTANICUS
}

Международный электронный журнал ботанических садов

\section{3 / 2018}

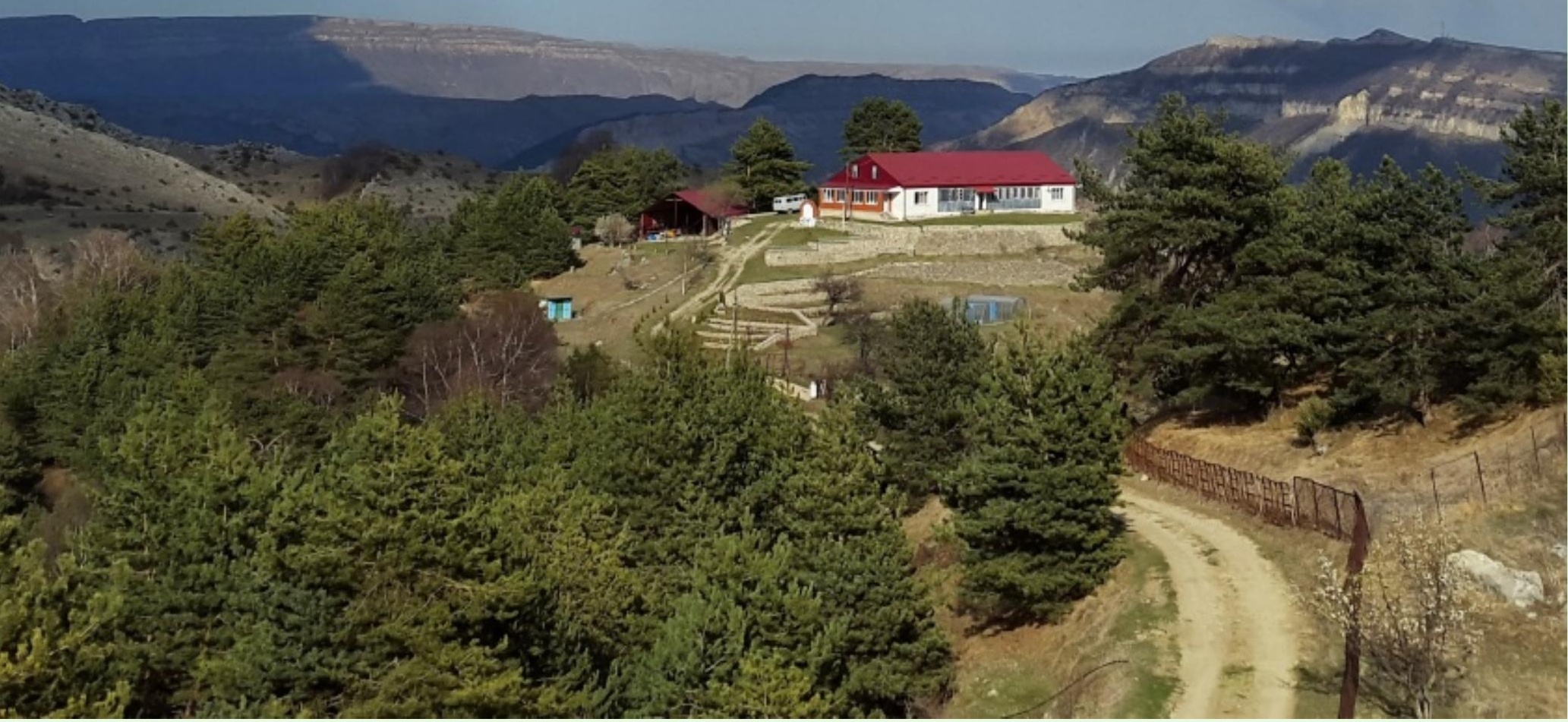


Информационно-аналитический центр Совета ботанических садов России при Ботаническом саде Петрозаводского государственного университета

\section{HORTUS BOTANICUS}

Международный электронный журнал ботанических садов

\section{$13 / 2018$}

ISSN 1994-3849

Эл № ФС 77-33059 от 11.09.2008

\section{Главный редактор}

А. А. Прохоров

Редакционный совет

П. Вайс Джексон Лей Ши Йонг-Шик Ким

А. С. Демидов

Т. С. Мамедов

В. Н. Решетников
Редакционная коллегия

Г. С. Антипина

Е. М. Арнаутова

А. В. Бобров

Ю. К. Виноградова

Е.В.Голосова

В. Я. Кузеванов

Е. Ф. Марковская

Ю. В. Наумцев

Е. В. Спиридович

К.Г. Ткаченко

А. И. Шмаков

\section{Редакция}

Е. А. Платонова

С. М. Кузьменкова

К. О. Романова

А. Г. Марахтанов

\section{Адрес редакции}

185910, Республика Карелия, г. Петрозаводск, ул. Красноармейская, 31, каб. 12.

E-mail:hortbot@gmail.com

http://hb.karelia.ru

(C) 2001-2018 A. А. Прохоров

\section{На обложке:}

Гунибская экспериментальная база Горного ботанического сада Дагестанского НЦ РАН

(фоото Руслана Османова)

\section{Разработка и техническая поддержка}

Отдел объединенной редакции научных журналов ПетрГУ, РЦ НИТ ПетрГУ,

Ботанический сад ПетрГУ

Петрозаводск 


\section{ВИРовский период научной деятельности Леонида Ивановича Рубцова: среди корифеев и будущих друзей}

$\begin{array}{ll}\text { РУБЦОВА } & \text { Национальный ботанический сад имени Н. Н. Гришко НАНУкраины, } \\ \text { Елена Леонидовна } & \text { olenarubtsova@gmail.com } \\ \text { чУвИКИНА } & \text { Национальный ботанический сад имени Н. Н. Гришко НАНУкраины, } \\ \text { Наталья Андреевна } & \text { natachko@ukr.net }\end{array}$

Ключевые слова:

наука, история, садоводство, ландшафтный дизайн, Всесоюзный институт растениеводства, Л. И. Рубцов, Сухуми, совхоз «Южные культуры», стадион имени С. М. Кирова, ВИР

\begin{abstract}
Аннотация: Всесоюзный институт растениеводства (ВИР) является мировым центром мобилизации растительных ресурсов, где среди ученых-корифеев приобретали опыт молодые исследователи. Среди них был и Леонид Иванович Рубцов, работавший в ВИРе в 1928-1930 гг. (Сухумское отделение) и в 1935-1939 гг. (Ленинград). Он занимался обследованием насаждений самшита и пробкового дуба в Сухуми, инвентаризацией парка «Южные культуры» в Адлере, изучением травосмесей и агротехники создания газонов для строящегося стадиона имени С. М. Кирова в Ленинграде. Результаты исследований Л. И. Рубцов опубликовал в журналах «Труды по прикладной ботанике, генетике и селекции», «Советские субтропики», «Зеленое строительство». Работа в ВИР, институте с мировым именем, дала Леониду Ивановичу Рубцову неоценимые знания и опыт, которые помогли ему в будущем стать известным ученым в области дендрологи и ландшафтной архитектуры, доктором биологических наук, профрессором, известным специалистом по созданию ботанических садов.
\end{abstract}

\section{Рецензент: Г. А. Солтани}

Всесоюзный институт растениеводства (ВИР; с 1894 - Бюро по прикладной ботанике и селекции, в 1924-1930 гг. - Всесоюзный институт прикладной ботаники и новых культур) - крупнейший научный и методический центр по растениеводству. Основная задача института - мобилизация мировых растительных ресурсов, их комплексное изучение и использование.

Начиная с 1921 г., ВИРом руководил Николай Иванович Вавилов (1887-1943), выдающийся ученыйгенетик, ботаник, селекционер, растениевод и географ, автор закона гомологических рядов в наследственной изменчивости организмов, создатель учения о биологических основах селекции и центрах происхождения и разнообразия культурных растений, академик АН СССР и АН УССР. С 1967 года институт носит имя академика Н. И. Вавилова, директора Института в период с 1921 по 1940 г.

Для своего Института Николай Иванович тщательно подбирал сотрудников, а потом следил за их ростом, помогал и направлял. «Вавиловская гвардия» не была однородной: она объединяла ученых разных поколений, выходцев из различных социальных слоев, воспитанников разных типов учебных заведений - сельскохозяйственных институтов и университетов, тех, кто пришли к Н. И. Вавилову вполне сорормировавшимися специалистами, и тех, формирование которых шло под влиянием Вавилова (Соратники ..., 1994).

Основную массу вавиловцев составляло второе поколение сотрудников. Это были молодые специалисты, пришедшие в ВИР сразу или вскоре после окончания ВУЗа. Все они сложились как ученые 
уже в Институте Вавилова, многие из них стали крупными учеными. Большинство вавиловцев, которые по той или иной причине покинули ВИР, оставались верными Николаю Ивановичу Вавилову и его идеям (Соратники ..., 1994). Для организации в институте новых лабораторий и отделов Н. И. Вавилов приглашал в ВИР крупных специалистов, уже имевших большой опыт руководства научными коллективами. Работа в таком мощном научном центре рядом с корифеями науки давала неоценимый опыт для молодых специалистов.

$\star \star$

\section{Сухуми}

Леонид Иванович Рубцов (1902-1980) доктор биологических наук, профессор, выдающийся дендролог и ландшафтный архитектор (рис. 1) также начинал свою научную деятельность в ВИРе: сначала в Сухумском отделении, еще будучи студентом Лесотехнической академии, которую он окончил в 1930 г. Как писал Л. И. Рубцов в автобиографии, в 1928-1930 гг. он работал техником в Сухумской опытной станции Всесоюзного института растениеводства. С 1935 по 1939 г. он работал старшим научным сотрудником ВИРа в Ленинграде (Леонід ..., 2012).

Все отделения ВИРа имели большие опытные поля и хорошо оснащенные лаборатории, в которых работали большие коллективы исследователей. В Сухумской опытной станции рядом с такими известными учеными, как первый директор Сухумской станции Н. Д. Костецкий (рис. 2), знатоки субтропической фрлоры СССР старший научный сотрудник, заместитель директора В. Ф. Николаев (рис. 3) (Самородов, Кигим, 2016), заведующий отделом дендрологии С. Г. Гинкул (рис. 4) (Васильев, 1941), работали молодые исследователи. Многие из них со временем также стали известными, а некоторые - даже знаменитыми: А. Л. Тахтаджян - в то время - лаборант, впоследствии - доктор биологических наук, академик АН СССР, в 1976-1986 директор Ботанического института имени В. Л. Комарова, создатель новой фрилогенетической системы высших растений и новой системы ботанико-географического районирования, получивших всемирное научное признание, известный специалист по луковичным растениям В. О. Алореров (рис. 5) (Константинов, 1937; Алферов, 1987), А. П. Витман - ботаник, специалист по диким плодовым растениям Кавказа (Диденко, 2000), член-корр. АН СССР Александр Александрович Федоров, в 1962-1976 гг. директор Ботанического института имени В. Л. Комарова АН СССР, член-корр. АН СССР Андрей Александрович Федоров, специалист по интродукции субтропических лекарственных растений, М. М. Молодежников (Лебединская, 1971), академик АН Таджикской ССР и АН Белорусской ССР Н. В. Смольский, в 1955-1976 гг. - директор Центрального ботанического сада АН БССР (Биологи ..., 1984).

Тридцатые годы XX века были периодом интенсивного развития субтропического сельского хозяйства СССР. Для обеспечения экономической независимости страны было необходимо полное прекращение импорта сырья, в том числе субтропического происхождения, и, соответственно, валютных расходов на чай, тунговое масло, цитрусовые, эфирные масла, пробку, гуттаперчу, декоративные и пряновкусовые растения, дубильные вещества, лекарственное сырье, ценные виды древесины. Для этого предусматривалось использовать благоприятные условия советских субтропиков, которые располагаются во влажной зоне на Черноморском побережье Кавказа.

В субтропических районах СССР были организованы специализированные научные учреждения, привлекались квалифицированные специалисты. Большое внимание уделялось изучению и оценке существующих естественных и созданных насаждений. Значительную роль в этих исследованиях сыграл Всесоюзный институт прикладной ботаники и новых культур (с 1930 г. - Всесоюзный институт растениеводства, ВИР).

В 1927-1928 гг. по заданию Сухумского отделения ВИР был проведен ряд обследований плодовых, дубильных, пряно-вкусовых, декоративных растений, а также древесных растений, которые имеют ценную древесину (Кварцхелиа, 1929). В этих работах принимал участие и студент Л. И. Рубцов. 

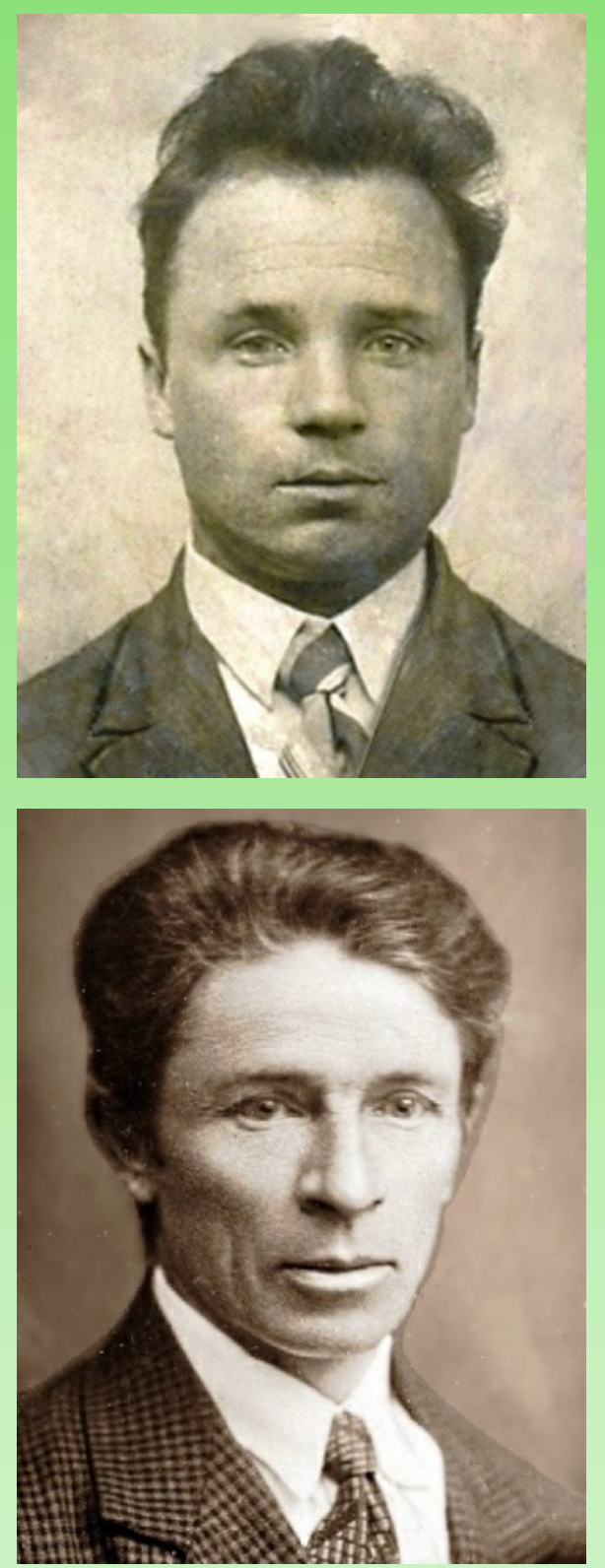

Рис. З. В. Ф. Николаев (Самородов, Кигим, 2016).

Fig. 3. V. F. Nikolaev (Samorodov, Kigim, 2016).
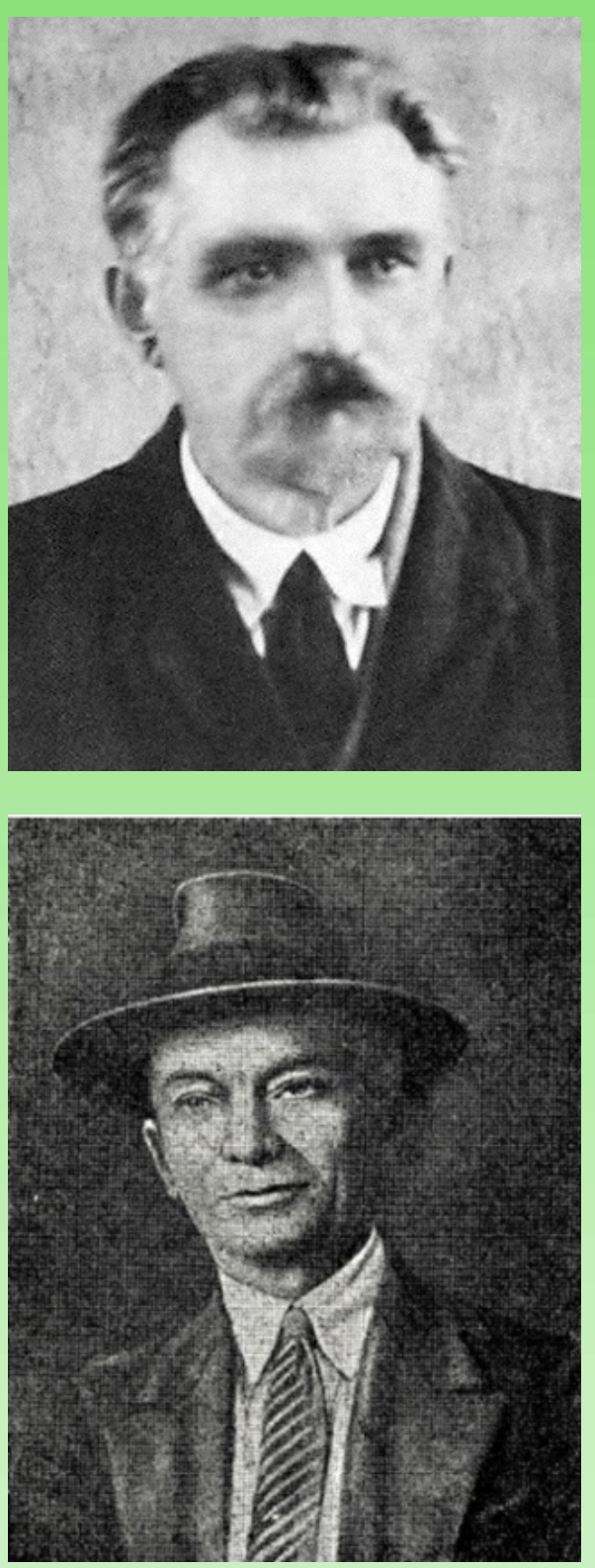

Рис. 4. С. Г. Гинкул (Васильев, 1941).

Fig. 4. S. G. Ginkul (Vasiliev, 1941).

Л. И. Рубцов учился в Ленинградской лесотехнической академии с 1923 по 1930 г. В автобиографии Леонид Иванович писал, что с 1928 по 1930 г. он работал техником в Сухумском отделении ВИРа. Известно, что в 1929 г. Л. И. Рубцов обследовал естественные насаждения самшита в пределах Закавказья (Кварцхелиа, 1929), а также рощу пробкового дуба в Агудзерах в окрестностях Сухуми (Рубцов, 1931). В связи с работой на Кавказе срок обучения в Академии растянулся на семь лет.

Самшит колхидский (Buxus colchica Pojark.) - третичный реликт, эндемик колхидско-лазистанской фрлоры, находящийся сегодня на грани полного исчезновения. Леонид Иванович занимался исследованием внутривидового разнообразия самшита колхидского в природных популяциях и изучением декоративных форм самшита в парковых насаждениях.

Академик Н. И. Вавилов в работе «Проблема новых культур» (Вавилов, 1931) среди перечня новых для СССР видов, которые заслуживают первоочередного внимания, отмечает пробковый дуб (Quercus suber L.). Пробково-изоляционное производство считалось одним из важнейших в CCCP. Ежегодная потребность в пробке была 10-12 тыс. т (Векслер, 1930). Сырье почти целиком ввозилось из-за границы. 
Постановлением Совета труда и обороны СССР от 10.01.1929 г. было признано необходимым ускорить работы по разведению в южных районах СССР пробкового дуба. К опытным работам по культуре и исследованиям пробкового дуба были привлечены учреждения Батуми, Сухуми, Ботанический сад г. Тифрлиса и Сухумское отделение Института прикладной ботаники (Векслер, 1930).

В Абхазии насаждения пробкового дуба были в двух районах - в Гагринском (1,5 га) и в Сухумском (1,5 га). Летом 1929 г. Л. И. Рубцов обследовал рощу пробкового дуба в Агудзерах под Сухуми. Эти посадки были заложены в 1900 г. семенами, полученными из Никитского ботанического сада. В Агудзерах было высажено 1800 сеянцев на площади около 3 га. При обследовании было обнаружено 246 деревьев. Были зафиксированы средний диаметр 38 см, средняя высота 15 м, урожай желудей с одного дерева 8-16 кг. Были отмечены также самосев пробкового дуба и порослевое возобновление.

Л. И. Рубцов пришел к выводу, что результаты интродукции и акклиматизации пробкового дуба в Абхазии удовлетворительные, он обладает большим приростом по высоте и диаметру, чем наиболее производительные насаждения Марокко и производит удовлетворительную по качеству пробку более быстрыми темпами, чем у себя на родине (Рубцов, 1931).

После окончания Лесотехнической академии Л. И. Рубцов в 1930-1932 гг. работал специалистом по лесным культурам в леспромхозе г. Туапсе, в 1932-1933 гг. - директором Жигулевского лесхоза (ныне Самарская область), в 1933-1935 гг. - научным сотрудником Всесоюзного института влажных субтропиков и заведующим субтропическим арборетумом (г. Сухуми). Результаты его работы в Институте влажных субтропиков опубликованы в двух статьях: «Инвентаризация Сухумского субтропического арборетума» (Рубцов, 1936г) и «Итоги интродукции древесных и кустарниковых пород в Сухумском субтропическом арборетуме» (Рубцов, 1937в). Причем вторая статья насчитывает 49 страниц.

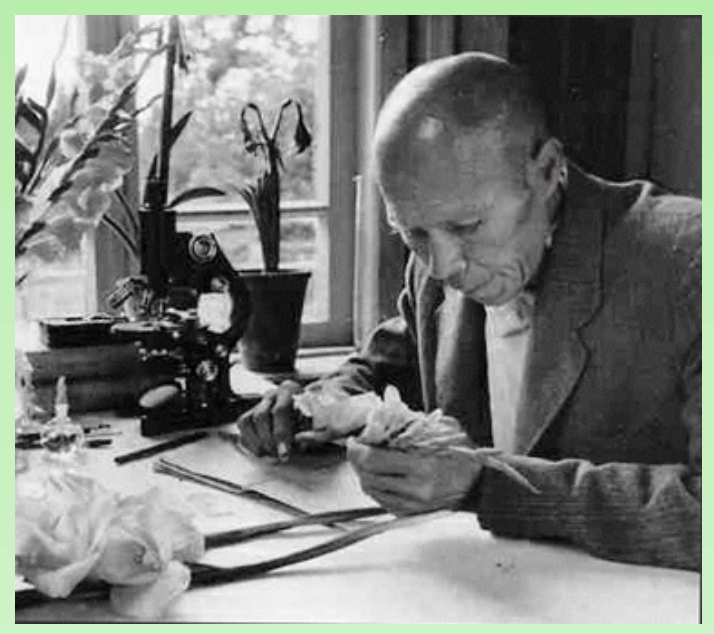

Рис. 5. В. А. Алфреров

Fig. 5. V. A. Alferov.

\section{Ленинград}

В 1935 г. Л. И. Рубцов переехал в Ленинград и начал работать в секции декоративных растений отдела новых культур и интродукции ВИРа (Леонід ..., 2012).

Отдел занимался интродукцией и изучением пищевых, масличных, текстильных, крахмало- и сахароносных, технических, кормовых, эфиро-масличных, каучуконосных, декоративных растений, а также содержащих красители и дубильные вещества. В секции садово-декоративных растений работали Н. И. Кичунов, П. И. Лапин, Н. А. Базилевская, Л. И. Рубцов (Шлыков, 1963). С некоторыми сотрудниками из многочисленного коллектива отдела интродукции (Н. В. Культиасовым, С. Г. Сааковым) Л. И. Рубцов работал впоследствии в Ботаническом институте (БИН), а с А. М. Кормилицыным, Н. В. Смольским, С. Г. Сааковым дружил до конца жизни.

Александр Михайлович Кормилицын (1908-1988) работал в ВИРе с 1931 по 1936 г. С 1936 г. он 
работал в Таджикистане, а в 1954 г. переехал в Крым, где на протяжении 23 лет заведовал отделом дендрологи и декоративного садоводства Никитского ботанического сада. В 1968-1974 гг. А. М. Кормилицын - заместитель директора по научной работе Никитского ботанического сада. Его большой заслугой было обоснование использования фрлорогенетического метода в интродукции растений (рис. 6) (Захаренко, Клименко, 2008).

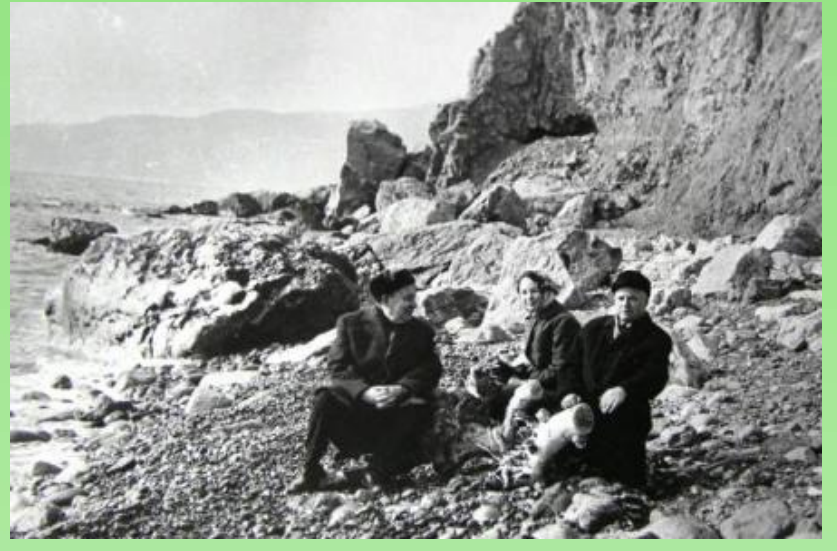

Рис. 6. А. М. Кормилицын, Е. Л. Рубцова (дочь Л. И. Рубцова) и Л. И. Рубцов в Крыму. 1974 г.

Fig. 6. A. M. Kormilitsyin, E. L. Rubtsova (the daughter of L. I. Rubtsov) and L. I. Rubtsov in Crimea. 1974.

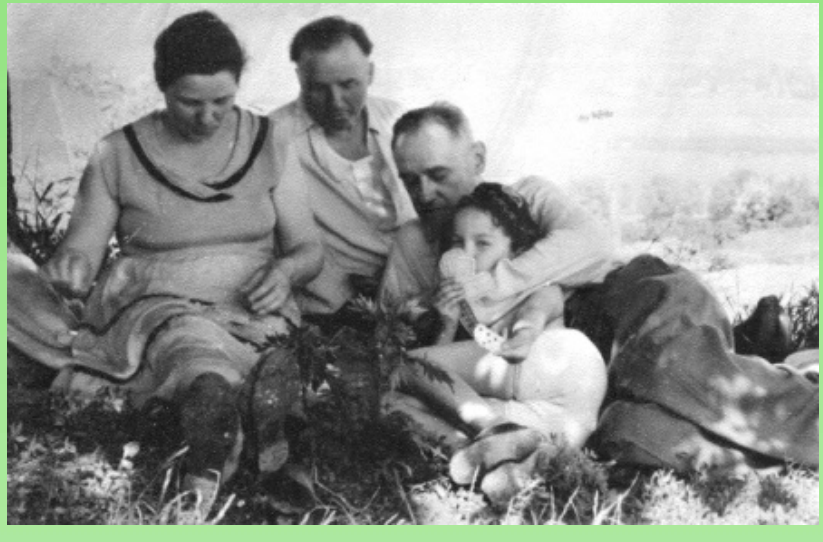

Рис. 7. Слева направо: В. К. Маркова (жена Л. И. Рубцова), Л. И. Рубцов, Н. В. Смольский, Елена Рубцова (дочь Л. И. Рубцова). 1956 г.

Fig. 7. From left to right: V. K. Markova (the wife of L. I. Rubtsov), L. I. Rubtsov, N. V. Smolskiy, Elena Rubtsova (the daughter of L. I. Rubtsov). 1956.

Николай Владиславович Смольский (1905-1976), в 1945-1955 - директор Всесоюзного научноисследовательского института сухих субтропиков в Душанбе, в 1951-1952 - исполняющий обязанности вице-президента АН Таджикской ССР, а в 1955-1976 - директор Центрального республиканского ботанического сада АН БССР, был приглашен в ВИР по рекомендации Н. И. Вавилова - сначала в Туркменское отделение, а в 1932 г. его перевели в Ленинград, на должность старшего научного сотрудника. Н. В. Смольский занимался изучением видового и сортового фронда шелковицы в СССР, плодовых культур Таджикистана. В последующие годы научная деятельность Н. В. Смольского проходила в Сухумском отделении ВИР, где он занимался исследованием интродукции и селекции тунгового дерева. Одновременно Н. В. Смольский занимался изучением возможности освоения других субтропических технических и декоративных растений, проводил большую научно-организационную работу (рис. 7) (Биологи ..., 1984).

Семен Григорьевич Сааков (1903-1984) - доктор биологических наук, выдающийся ботаник, цветовод (рис. 8) в 1937 г. перешел на работу в ботанический сад БИНа, где в течение многих лет заведовал оранжереей. Самые значимые монографии: «Газоны и цветочные растения» (1954), «Пальмы и их культура в СССР» (1954), «Розы» (1973), «Оранжерейные и комнатные растения и уход за ними» (1983).

Секция декоративных растений ВИР была немногочисленная, но ее возглавляли профессора, выдающиеся специалисты-цветоводы: с 1931 - Н. И. Кичунов, а с 1937 - Н. А. Базилевская (Тамберг, 1986; Соратники ..., 1994).

Николай Иванович Кичунов (1863-1942) - доктор сельскохозяйственных наук, известный плодовод, овощевод, цветовод, обладал талантом популяризатора науки. Он был автором 106 книг, в том числе 38 по цветоводству, 22 - по овощеводству, 16 - по декоративному садоводству, остальные - по общим вопросам садоводства. С 1921 по 1929 г. он был профессором и заведующим кафедрой садоводства Ленинградского сельскохозяйственного института. Одновременно (с 1922 г.) работал во Всесоюзном институте прикладной ботаники и новых культур (ВИР). Он был организатором и членом жюри всех крупных выставок по садоводству (Тамберг, 1986).

Нина Александровна Базилевская (1921-1997) - известный ботаник, доктор биологических наук, профрессор Московского государственного университета (МГУ), директор Ботанического сада биологического фракультета МГУ (1952-1964), ученица и одна из ближайших соратниц академика Н. И. 
Вавилова, специалист в области интродукции растений. Она опубликовала большое количество статей и книг по теории и методам интродукции растений, истории науки, цветоводству, озеленению (Юбилей ..., 1962).

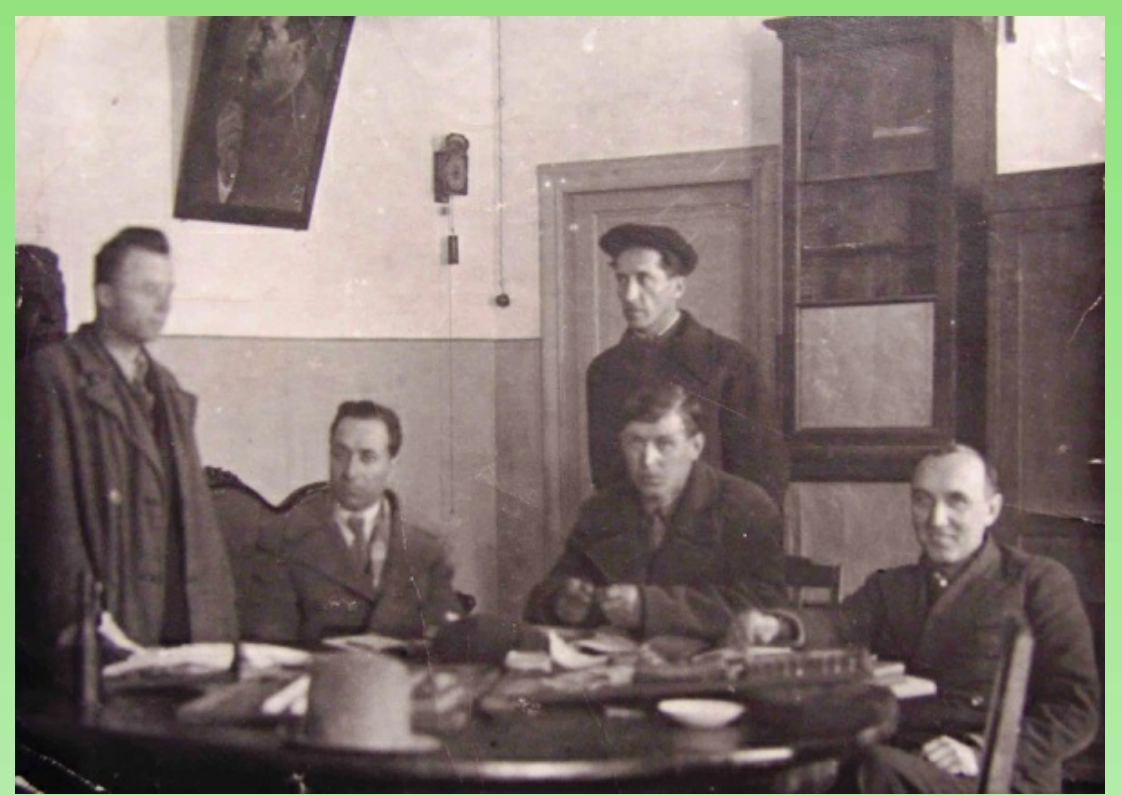

Рис. 8. С коллегами Ботанического института. Первый слева Л. И. Рубцов, второй С. Г. Сааков. 1945 г.

Fig. 8. With colleagues from the Botanical Institute. First on the left L. I. Rubtsov, second on the left S. G. Saakov, 1945.

В 1939 г. в г. Сочи под председательством академика Н. И. Вавилова проходил Первый выездной пленум секции субтропических культур Академии сельскохозяйственных наук, посвященный вопросам развития цветоводства и декоративного садоводства в СССР (Малько и др., 1939). Н. А. Базилевская в докладе «Состояние и задачи научно-исследовательской работы по цветоводству в СССР», отметила, что в 1926 г. ВИР начал плановую интродукцию декоративных растений. За период с 1926 г. по 1938 г. Институтом получено из-за границы свыше 3000 сортов основных декоративных культур и передано производству в виде луковиц, корневищ и саженцев в количестве 900000 экземпляров и 100 кг семян. Кроме того, проводилась большая работа по внедрению в культуру декоративных растений природной фрлоры СССР. Было испытано и передано производству 240 видов красивоцветущих растений Дальнего Востока, Кавказа и Средней Азии. Велись работы по регулированию цветения астр, левкоев, георгин, хризантем, гвоздики. Разрабатывалась методика селекции и семеноводства декоративных растений (Базилевская, 1939). В 1939 г. аспирант ВИРа Петр Иванович Лапин защитил кандидатскую диссертацию «Управление цветением декоративных растений».

Петр Иванович Лапин (1909-1986) стал известным специалистом в области использования растительных ресурсов, интродукции и акклиматизации растений, доктором биологических наук, членомкорреспондентом АН СССР. Основные научные исследования посвящены разработке теоретических основ интродукции и акклиматизации древесных растений, декоративного садоводства. С 1945 г. работал в Главном ботаническом саду (Москва). С 1948 г. заведовал отделом дендрологии, а с 1952 г. был заместителем директора ГБС по научной работе (Биологи ..., 1984).

Одними из главных задач ВИР являлись: выработка и расширение ассортимента декоративных растений для различных зон Советского Союза; введение в культуру диких видов из фрлоры СССР и создание новых сортов. Большое внимание уделялось изучению зимней выгонки цветущих растений и расширению ассортимента комнатных растений (Базилевская, 1939).

Результаты исследований сотрудники секции декоративных растений публиковали в сборнике «Зеленое строительство», который был организован по решению Пленарного заседания секции субтропических культур Всесоюзной академии сельскохозяйственных наук и Биологической ассоциации АН СССР. Организация сборника и его редактирование было поручено А. М. Лежаве, академику Н. И. Вавилову и академику Б. А. Келлеру (Резолюции ..., 1936). 


\section{Инвентаризация парка совхоза «Южные культуры»}

В середине 30X гг. XX столетия Главное управление субтропических культур Наркомзема СССР постановило провести инвентаризацию парков Черноморского побережья. Так как Л. И. Рубцов имел опыт работы с субтропическими растениями на Кавказе, именно ему в 1936 г. поручили инвентаризацию парка «Южные культуры» (Адлер).

Инвентаризацию парка совхоза «Южные культуры» провела бригада научных работников во главе с Л. И. Рубцовым. В результате было отмечено 379 видов, разновидностей и форм в количестве 5420 экземпляров (Рубцов, 1937а, 1936б).

Парк совхоза «Южные культуры» (бывшее имение «Случайное» генерала Д. В. Драчевского) принадлежит к группе пяти наиболее известных на Черноморском побережье парков (Солтани, 2014). Л. И. Рубцов отмечает, что уступая по разнообразию растительных фрорм Никитскому ботаническому саду, Сочинскому дендрарию, Сухумскому арборетуму и Батумскому ботаническому саду, он превосходит их по планировке и устройству. Проект разбивки парка был исполнен выдающимся специалистом по садовопарковому искусству Арнольдом Регелем, автором известной уникальной книги «Изящное садоводство и художественные сады» (Рубцов, 1937а; Солтани, 2014). Основная территория парка спланирована в ландшафтном стиле, имеется также изысканный регулярный партер (рис. 9) (Колесников, 1949). Отличительной особенностью парка является преобладание равнинного рельесра, наличие крупных партерных зон со стрижеными фрормами, широких аллей из крупных деревьев, обилием хвойных деревьев. Парк украшают два искусственных пруда.

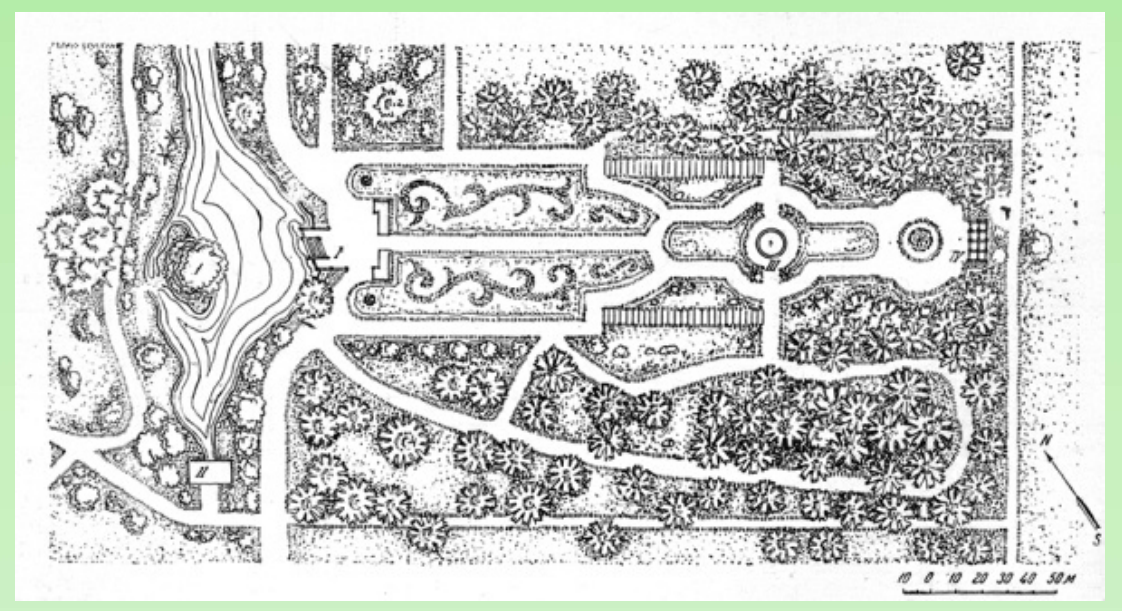

Рис. 9. Партер в парке совхоза «Южные культуры» (Колесников, 1949).

Fig. 9. The Parterre in the park of the state farm "Southern cultures" (Kolesnikov, 1949).

В результате детального изучения парка совхоза «Южные культуры» Л. И. Рубцов подготовил путеводитель по этому парку и составил предложения по его реконструкции (рис. 10) (Рубцов, 1936б, 1937a).

Анализ биоразнообразия субтропических парков и их ландшафртного планирования дал возможность Л. И. Рубцову сформулировать оригинальные выводы и предложения по особенностям ландшастного проектирования субтропических парков.

Л. И. Рубцов считал, что, приступая к созданию субтропического парка, ландшафртный архитектор должен в первую очередь обеспечить вечнозеленость путем введения не менее 79-80 \% вечнозеленых видов. При подборе вечнозеленых видов нужно избегать большого количества хвойных, т. к. преобладание хвойных растений стушевывает разницу между парком северной и субтропической зоны и придает парку тяжелый и мрачный облик. В среднем хвойные, по мнению Л. И. Рубцова, должны занимать по количеству около 30 \% всего состава вечнозеленых видов. 


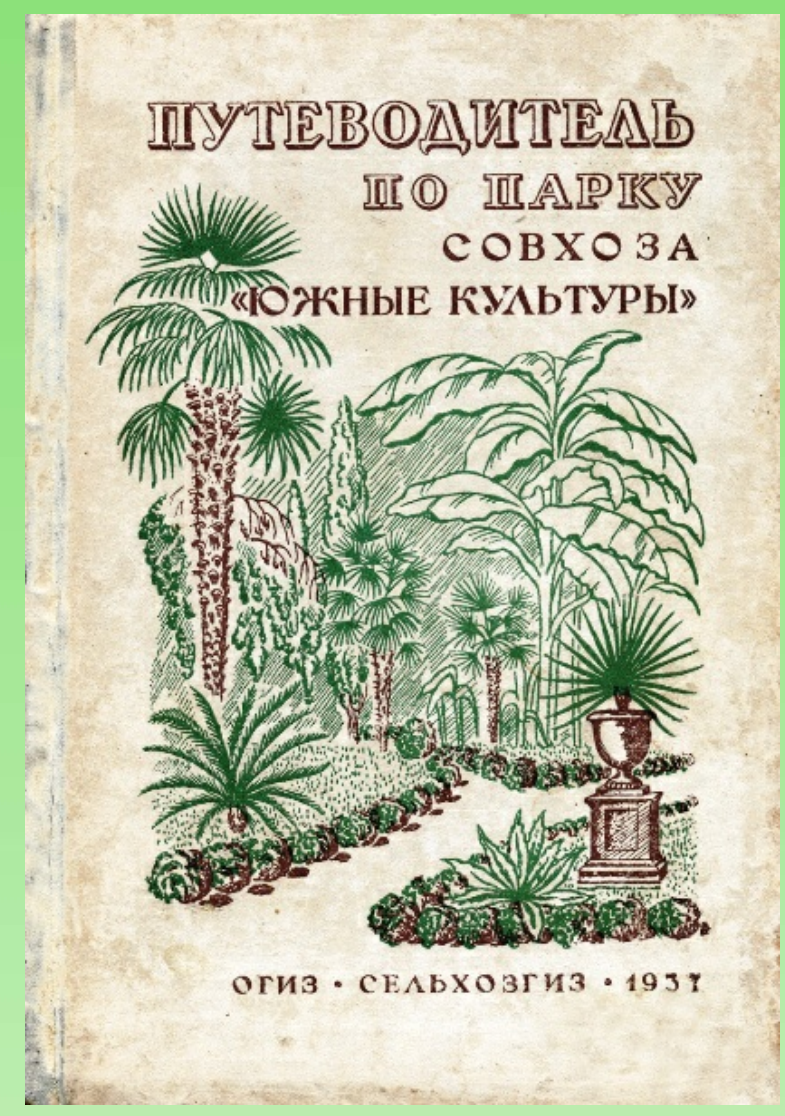

Рис. 10. Путеводитель по парку совхоза «Южные культуры».

Fig. 10. Guide to the park of the state farm "Southern cultures".

Листопадные деревья субтропического парка должны отличаться особыми характерными чертами, выделяющими их от облика северных видов. Такими характерными чертами могут быть необычайно крупные листья (павловния, стеркулия) или листья, красивые по окраске (японский клен, тюльпанное дерево, гинкго).

Л. И. Рубцов писал, что по мере продвижения с севера на юг мы наблюдаем два характерные изменения в растительном мире. Первое - роскошь цветов, характерная в северной и умеренной полосе для травянистых растений, при продвижении к югу поднимается все выше и выше от земной поверхности. В субтропическом климате наибольшее цветочное убранство ландшафрта создают не травянистые растения, а великолепно цветущие кустарники, полукустарники и небольшие деревца. В тропическом климате цветы перекочевывают на деревья, и деревья обладают самым роскошным нарядом.

Второй характерной особенностью является большое участие лиан в общем облике ландшаста.

Анализ существующего ассортимента древесной растительности дал возможность Л. И. Рубцову рекомендовать лучшие древесные и кустарниковые виды растений для озеленения Черноморского побережья Кавказа (Рубцов, 1936а).

Начиная со студенческих лет, Л. И. Рубцов детально изучал природную и культурную фрлору, а также особенности парков субтропических районов Кавказа. Результаты его деятельности изложены в работах тех лет.

\section{Стадион имени С. М. Кирова}

Всесоюзный институт растениеводства принимал активное участие в озеленении Ленинграда.

В 30е годы XX века в рамках “социалистической реконструкции Ленинграда», по инициативе Сергея Мироновича Кирова было решено создать на Крестовском острове Ленинграда центр активного отдыха - 
фризкультуры, спорта и массовых народных гуляний. Для решения этой задачи в западной части острова предполагалось построить огромный стадион на 100 тысяч зрителей - самый большой в Советском Союзе.

Проектирование столь масштабного сооружения было осуществлено известным архитектором Академии художеств Александром Сергеевичем Никольским (рис. 11). Спроектированный А. С. Никольским стадион должен был иметь фрорму холма и быть выполненным из земли, камня и железобетона. Внутренние склоны холма образовывали чашу для зрительских трибун. Внешняя сторона холма представляла собой чередование террас и пологих зеленых склонов (Стадион ...). В 1935 г. началось строительство стадиона, который был назван в честь советского государственного и политического деятеля Сергея Мироновича Кирова.

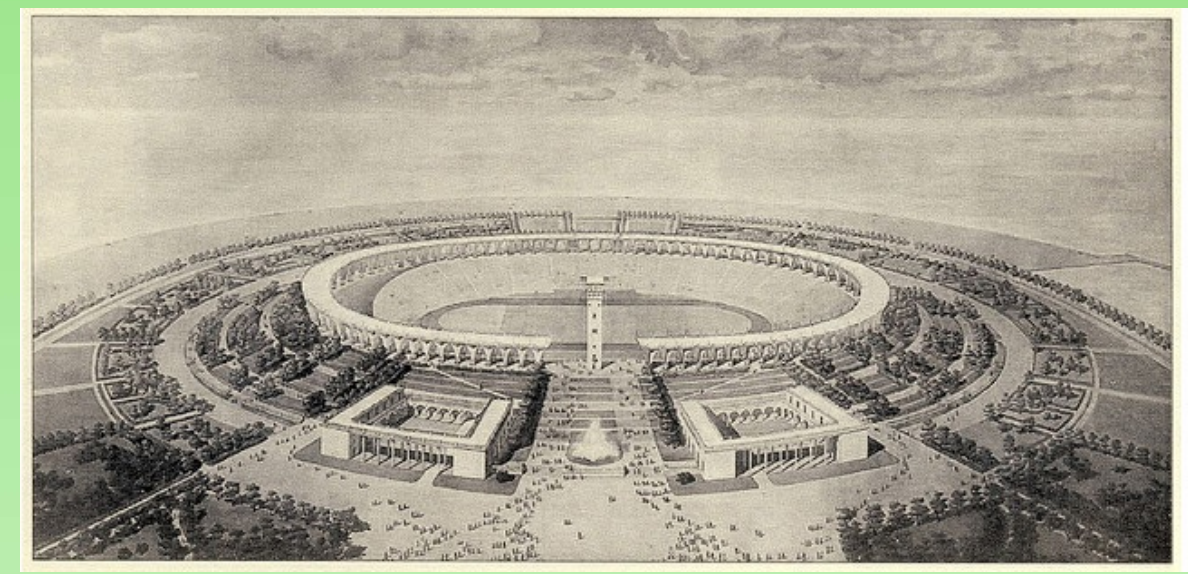

Рис. 11. Проект стадиона. Архитектор А. С. Никольский (http:// piterarena.com/istoriya).

Fig. 11. Project of the stadium. Architect A. S. Nikolskiy.

Важным элементом для создания будущего стадиона было устройство спортивного газона. С этой целью организация, занимающаяся строительством, заключила договор с ВИРом на проведение опытов по подбору травосмесей и агротехнике создания устойчивых многолетних газонов. Указанными исследованиями занимались научный сотрудник ВИРа Л. И. Рубцов и садовод С. К. Старк (Рубцов, 1938б).

В задачу исследователей входила разработка методики создания газонов четырех типов: обычных 17 га, спортивных, трудно поддающихся вытаптыванию - 6 га, упрощенного типа (характера обычного луга) - 40 га и цветущих (мавританских) - 9 га.

Для выполнения поставленной задачи были продолжены опытные работы, начатые Ботаническим институтом (БИН) в 1935 г., но, по разным причинам, не законченные.

Необходимо было определить состав смеси газонных трав и разработать необходимый слой насыпной земли, главнейшие приемы агротехники, учитывая, что будущий стадион строился на песке.

Для выполнения задачи были изучены результаты опытов БИНа, опыт питомника Всесоюзного Совета фризической культуры в Москве, а также по литературным источникам - опыт создания игровых полей в Англии, Канаде и США.

На специальном питомнике будущего стадиона имени С. М. Кирова была заложена маточная семенная плантация площадью 0,3 га из семян репродукции ВИРа. Кроме того, для получения цветущих газонов выписано из ботанических садов Европы 500 образцов семян различных многолетников, которые были высеяны для изучения. Исследования проводились в течение двух вегетационных периодов (1938-1939 гг.) до начала предполагаемого строительства стадиона (1940 г.). Результаты исследований были опубликованы Л. И. Рубцовым в журнале «Зеленое строительство» в 1938 г. и 1939 г. (Рубцов, 1938б, 1939a). Для создания цветущих многолетних газонов автор рекомендовал использовать виды гвоздик. Особенно он выделил Dianthus deltoides L., которая в 1938 г. на песчаной почве без полива дала прекрасный цветущий газон (Рубцов, 1939а). Строительство стадиона было прервано войной 1941-1945 гг. и блокадой Ленинграда. 
В апреле 1939 г. Л. И. Рубцов перешел на работу в отдел Ботанический сад Ботанического института, где он плодотворно работал до 1948 г. (за исключением 1941-1945 гг., когда он принимал участие в боевых действиях) (Леонід ..., 2012).

\section{Теоретические вопросы садово-парковой архитектуры}

Одновременно с работой в ВИРе Л. И. Рубцов с 1936 по 1941 г. вел доцентский курс по ландшафтному садоводству в Лесотехнической академии имени С. М. Кирова и занимался теоретическими вопросами садово-парковой архитектуры нашедшими отражение в его работах: «Перспектива и ее значение в ландшасртном строительстве» (Рубцов, 1937б), “Альпийский сад» (Рубцов, 1938в), “Свет и тени в парковых композициях» (Рубцов, 1938а), «Ранне-весеннее цветочное офрормление парков» (Рубцов, 1939б). На совещании секции древесных технических и декоративных растений ВИРа Л. И. Рубцов выступил с докладом «Современные принципы паркового строительства» (Рубцов, 1936в).

$\star * *$

Работа во Всесоюзном институте растениеводства, Институте с мировым именем, а также в выдающемся научном центре, Ботаническом институте имени В. Л. Комарова, рядом с корифреями науки дала Леониду Ивановичу Рубцову неоценимые знания и опыт, которые помогли ему в будущем стать известным ученым в области дендрологии и ландшафтной архитектуры, доктором биологических наук, профрессором, известным специалистом по созданию ботанических садов (Чувикина, 2012; Рубцова, 2016; Рубцова, Романец, 2016). С некоторыми сотрудниками ВИРа и БИНа Л. И. Рубцов дружил до конца жизни.

За выдающие заслуги в области ландшафтной архитектуры Л. И. Рубцов включен в рейтинг архитекторов республик Советского Союза как архитектор, который получил высокую оценку профрессиональных обществ (Справочник ...).

\section{Литература}

Алсреров В. А. Постоянно в дороге [Constantly on the road.] // Вавилов Н. И. Очерки, воспоминания, материалы. [Vavilov N. I. Essays, memoirs, materials.] M., 1987. С. 251-253.

Базилевская Н. А. Состояние и задачи научно-исследовательской работы по цветоводству в СССР // Вопросы цветоводства и декоративного садоводства в СССР. Тез. докл. на V выездном пленуме секции субтропических культур 15-20 апреля 1939 г. [State and tasks of scientific research on floriculture in the USSR // Issues of floriculture and decorative gardening in the USSR. Proceeding of the $\mathrm{V}$ offsite plenum of the section of subtropical crops, April 15-20, 1939] M., 1939. C. 14-16.

Биологи. Биографрический справочник. [Biologists. Biographical reference book.] Киев, 1984. 815 c.

Вавилов Н. И. Проблема новых культур // Социалистическое растениеводство. [The problem of new cultures // Socialist plant growing.] 1931. № 1. C. 151-181.

Васильев А. В. Сергей Григорьевич Гинкул // Советская ботаника. [Sergiy Grigorievich Ginkul // Soviet botany.] 1941. № 3. C. 202-203.

Векслер А. И. На субтропическом фрронте // Субтропики. [On the subtropical front // Subtropics.] 1930. № 712. C. 3-13.

Диденко Н. В. Александр Петрович Витман // Сочинский краевед. [Alexandr Petrovich Vitman // Sochi Regional Ethnographer]. 2000. Вып. 9. URL: apsnyteka.org/file/sotchinsky_kraeved_9.doc .

Захаренко Г. С., Клименко З. К. Жизненный и творческий путь А. М. Кормилицына // Труды Никитского ботанического сада. [Life and creative path of A. M. Kormilitsyn // Proceedings of the Nikita Botanical Garden.] 2008. T. 130. C. 12-15.

Кварацхелиа Т. К. Естественно-историческое и агрономическое обследование субтропиков // Субтропики. [Natural-historical and agronomical survey of subtropics // Subtropics.] 1929. №1—2. C.41—49. 
Колесников А. И. Архитектура парков Кавказа и Крыма. [Architecture of parks of the Caucasus and Crimea.] М., $1949.176 \mathrm{c}$.

Константинов М. К. Теснее связаться с производством (Работа Интродукционного питомника) // Советские субтропики. [Closer contact with production (Work of introductional seed plot) // Soviet subtropics.] 1937. № 12. С.17-22.

Лебединская В. "Я берег эту плантацию пуще жизни..." // Вокруг Света. ["I am taking care of this plantation more than my life ..." // Around the World] 1971. № 6. С. 23-27.

Леонід Іванович Рубцов (1902-1980): біобібліографія [Leonid Ivanovych Rubtsov (1902-1980): biobibliography.] / Уклад.: О. Л. Рубцова, Н. В. Чувікіна, Л. О. Ісакова; відп. редактор М. І. Шумик. Київ, 2012, $32 \mathrm{c}$.

Малько И. М., Машинский Л. О., Рубцов Л. И., Сааков С. Г. Первый пленум Академии сельскохозяйственных наук по вопросу развития цветоводства и декоративного садоводства в г. Сочи // Зеленое строительство. [The first plenum of the Academy of Agricultural Sciences on the development of floriculture and decorative gardening in Sochi // Green building.] 1939. № 3-4. C. 8-15.

Резолюции пленарного заседания секции субтропических культур Всесоюзной академии сельскохозяйственных наук им. В. И. Ленина и Биологической ассоциации АН СССР // Советские субтропики. [Resolutions of the plenary session of the section of subtropical crops of the All-Union Academy of Agricultural Sciences named after Lenin and of the Biological Association of the Academy of Sciences of the USSR // Soviet subtropics.] 1936. № 4. C. 110-113.

Российский государственный архив кинофотодокументов. Шифр: 0-207701. Алферов В. Цветовод Черноморского совхоза "Южные культуры". [Russian State Archive of Film and Photo Documents. Code: 0207701. Alferov V. The flower-grower of the Black Sea state farm "Southern cultures".] URL: http://www.photo.rgakfd.ru/showObject.do?object=1804493411 .

Рубцов Л. И. Агудзерская пробковая роща // Труды по прикладной ботанике, генетике и селекции. [Agudzer cork grove // Proceedings on applied botany, genetics and breeding.] 1931. Т. 27. № 3. C. 41-54.

Рубцов Л. И. Ассортименты лучших древесных и кустарниковых пород для озеленения Черноморского побережья Кавказа // Советские субтропики. [Assortments of the best wood and shrub cultivars for gardening of the Black Sea coast of the Caucasus // Soviet subtropics]. 1936a. № 4. C. 126-127.

Рубцов Л. И. Реконструкция парка "Южные культуры" // Советские субтропики. [Reconstruction of the park "Southern Cultures" // Soviet subtropics.] 1936б. № 11. С. 74-78.

Рубцов Л. И. Совещание представителей дендросекторов при Секции древесных технических и декоративных растений ВИРа // Зеленое строительство [Meeting of representatives of dendrosectors at the Section of wood technical and decorative plants of VIR // Green Building], 1936в. № 2—3. С. 99-100.

Рубцов Л. И. Инвентаризация Сухумского субтропического арборетума // Советские субтропики. [Inventory of the Sukhumi subtropical arboretum // Soviet subtropics.] 1936r. № 3. C. 54-59.

Рубцов Л. И. Путеводитель по парку совхоза "Южные культуры". [Guide to the park of the state farm "Southern cultures".] M., 1937a. 112 c.

Рубцов Л. И. Перспектива и ее значение в ландшафртном садоводстве // Зеленое строительство. [Perspective and its importance in landscape gardening // Green building.] 1937б. № 11—12. С. 31—40.

Рубцов Л. И. Итоги интродукции древесных и кустарниковых пород в Сухумском субтропическом арборетуме // Труды интродукционного питомника субтропических культур. [Results of introduction of tree and shrubby species in the Sukhumi subtropical arboretum // Proceeding of the introductory seed plot of subtropical cultures.] 1937в. № 2. C. 5-54.

Рубцов Л. И. Свет и тени в парковых композициях // Зеленое строительство. [Light and shadows in park compositions // Green building.] 1938. № 1. С. 45-52. 
Рубцов Л. И. К постановке опытных работ по устройству трудно вытаптываемых и цветущих газонов на строительстве стадиона им. С. М. Кирова // Зеленое строительство. [То the statement of experimental works on the arrangement of difficultly-trampled and blooming lawns on the construction of the stadium named after $\mathrm{S}$. M. Kirov // Green building.] 1938. № 4. C. 45-51.

Рубцов Л. И. Альпийский сад // Зеленое строительство. [Alpine Garden // Green Building.] 1938. № 18. С. 55 $-64$.

Рубцов Л. И. Почвопокровные, заменяющие злаковый газон, растения // Зеленое строительство. [Groundcovering plants, replacing the grass lawn // Green building.] 1939. № 1-2. С. 41-45.

Рубцов Л. И. Ранне-весеннее цветочное офрормление парков // Зеленое строительство. [Early-spring floral decorating of parks // Green building.] 1939. № 56. С. $2-9$.

Рубцова Е. Л. Вклад доктора биологических наук, профессора Л. И. Рубцова в проектирование и строительство парков Украины // Інтродукція рослин. [Contribution of doctor of biological sciences, professor L. I. Rubtsov to the design and construction of Ukrainian parks // Plant Introduction.] 2016. № 3. C. 64-74.

Рубцова Е. Л., Романец Е. И. Вклад доктора биологических наук, профессора Л.И. Рубцова в создание ботанических садов // Інтродукція рослин. [Contribution of doctor of biological sciences, professor L. I. Rubtsov to the creation of botanical gardens // Plant Introduction.] 2016. № 1. C. 41-49.

Самородов В. М., Кигим С. А. Постаті природознавства та музейництва полтавщини (XIX-XX ст.). [Personalities of natural science and museology of Poltava region (XIX-XX centuries).] Полтава, 2016. 144 с.

Солтани Г. А. История создания дендропарка "Южные культуры" (персоны и события) // Hortus Botanicus. [The history of the creation of the dendrological park "Southern cultures" (persons and events) // Hortus Botanicus.] 2014. № 9. C. 22-33; URL:hb.karelia.ru/ .

Соратники Вавилова - исследователи генофонда растений. [Vavilov's companions-researchers of the gene pool of plants.] СПб., 1994. 607 c.

Справочник "Единый художественный рейтинг". [Directory "United artistic rating".] URL: http://rating.artunion.ru

Стадион Никольского. [Nikolsky Stadium.] URL: http:// piterarena.com/istoriya .

Тамберг Т. Г. Садовод-энциклопедист // Цветоводство. [Gardener-encyclopedist // Floriculture.] 1986. № 3. С. 39.

Чувикина Н. В. Научная деятельность Леонида Ивановича Рубцова в Национальном ботаническом саду им. Н. Н. Гришко НАН Украины // Международные чтения, посвященные 110-летию со дня рождения доктора биологических наук, профессора Леонида Ивановича Рубцова: материалы конференции. [Scientific activity of Leonid Ivanovich Rubtsov in the N. N. Gryshko National Botanical Garden, National Academy of Sciences of Ukraine // International readings devoted to the 110th anniversary of the birth of doctor of biological sciences, professor Leonid Ivanovich Rubtsov: conference proceedings.] Киев, 2012. С. 68-72.

Шлыков Г. Н. Интродукция и акклиматизация растений. [Introduction and acclimatization of plants.] M., 1963. 488 c.

Юбилей профрессора Н. А. Базилевской // Вестник Московского университета. [Anniversary of the professor N. A. Bazilevskaya // Bulletin of Moscow University.] 1962. № 5. C. 76-80. 


\section{The period of scientific activity of Leonid Ivanovich Rubtsov at N.I. Vavilov Institute of Plant Industry (VIR): among luminaries and future friends}

\begin{tabular}{ll}
$\begin{array}{l}\text { RUBTSOVA } \\
\text { Elena }\end{array}$ & $\begin{array}{l}\text { N. N. Gryshko National Botanical Garden, National Academy of Sciences of Ukraine, } \\
\text { olenarubtsova@gmail.com }\end{array}$ \\
\hline $\begin{array}{l}\text { CHUVIKINA } \\
\text { Nataliia }\end{array}$ & $\begin{array}{l}\text { N. N. Gryshko National Botanical Garden, National Academy of Sciences of Ukraine, } \\
\text { natachko@ukr.net }\end{array}$
\end{tabular}

\section{Key words:}

science, history, horticulture, landscaping, the All-Union Institute of Plant Industry, Sukhumi, the park of the state farm "Southern

Cultures", stadium named after S.

M. Kirov, VIR

\begin{abstract}
Summary: The All-Union Institute of Plant Industry (VIR) is the world center for the mobilization of plant resources, where young researchers gained experience in the company of luminary scientists. Among them was Leonid Ivanovich Rubtsov, who worked at VIR in 1928-1930 (Sukhumi branch) and in 1935-1939 (Leningrad). He examined the plantations of boxwood and cork oak in Sukhumi, made inventory count at the "Southern Cultures" Park in Adler, studied grass mixtures and agrotechnics to create lawns of the Stadium n.a. S.M. Kirov in Leningrad. The results of L.I. Rubtsov's researsh are published in such magazines as "Works on applied botany, gentics and selection", "Sovit Subtropics" and "Green Construction". The work at VIR, a world-renowned institution, gave to Leonid Ivanovich Rubtsov invaluable knowledge and experience that helped him become a well-known scientist in the field of dendrology and landscape architecture, a doctor of biological sciences, a professor, a well-known specialist in the creation of botanical gardens.
\end{abstract}

Reviewer: G. Soltani

Цитирование: Рубцова Е. Л., Чувикина Н. А. ВИРовский период научной деятельности Леонида Ивановича Рубцова: среди корифреев и будущих друзей // Hortus bot. 2018. T. 13, 2018, стр. 4 - 16, URL: http://hb.karelia.ru/journal/atricle.php?id=5282. DOI: 10.15393/j4.art.2018.5282

Cited as: Rubtsova E., Chuvikina N. (2018). The period of scientific activity of Leonid Ivanovich Rubtsov at N.I. Vavilov Institute of Plant Industry (VIR): among luminaries and future friends // Hortus bot. 13, 4 - 16. URL: http://hb.karelia.ru/journal/atricle.php?id=5282 